\title{
CENTRO HISTÓRICO DE DRACENA: IDENTIDADE E SALVAGUARDA
}

Luiza Sobhie Muñoz, Hélio Hirao

Universidade Estadual Paulista, Faculdade de Ciências e Tecnologia. Curso de Arquitetura e Urbanismo, Programa Renove-PROPe. E-mail: luiza munoz@hotmail.com

\section{RESUMO}

Este artigo trata sobre a permanência das paisagens iniciais no centro histórico de Dracena identificando e mapeando o conjunto de elementos arquitetônicos e urbanísticos significativos, tanto históricos quanto culturais, que caracterizam a sua paisagem. Dracena é uma cidade da região de Presidente Prudente, fundada em 1945, situada numa área mais conhecida como Nova Alta Paulista, que surge em função do avanço dos trilhos da Companhia Paulista de Estradas de Ferro. Essa investigação tem o intuito de constatar o processo de descaracterização e abandono de tais centros. Discute-se, portanto, a função e significado desses centros históricos no cotidiano da cidade atual ao verificar como a população os reconhecem e se apropriam. O levantamento destes dados possibilita subsidiar encaminhamentos de ações para sua salvaguarda, impedindo que este importante suporte material da memória da cidade se perca com o passar do tempo, fortalecendo a identidade local.

Palavras-chave: Centro histórico; Preservação; Paisagem Urbana; Dracena; Ferrovia.

\section{HISTORICAL CENTRE OF DRACENA: IDENTIFY AND SAFEGUARD}

\begin{abstract}
This article is about the permanence of the initial landscapes in the historic center of Dracena identifying and mapping the set of significant architectural and urban planning, both historical and cultural elements that characterize its landscape. Dracena is a city of Presidente Prudente region, founded in 1945, located in the area known as New Alta Paulista, which arises due to the advancement of rails Company of Railroads. This research aims to observe the process of adulteration and dumping of these centers. It is argued, therefore, the function and significance of these historic centers in the daily life of the modern city to see how the people recognize and appropriate. The survey data allows these referrals subsidize shares for its preservation, preventing this important material memory of the city to lose support over time, strengthening local identity.
\end{abstract}

Keywords: Historic center; preservation; Urban Landscape; Dracena; Railroad. 


\section{INTRODUÇÃO}

A investigação levanta e identifica a paisagem característica de Dracena, cidade situada na região de Presidente Prudente, que ainda apresenta suportes materiais do início de sua ocupação. Essas características históricas permanecem, definem o seu caráter e identificam a cidade.

A cidade é produto material dos recursos econômicos proporcionados pelo cultivo do café, algodão e amendoim e, consequente avanço dos trilhos da Estrada de Ferro no Estado de São Paulo. Enquanto essas culturas procuraram novas terras férteis, abandonando as utilizadas a exaustão, nos núcleos urbanos iniciais, paisagens características foram produzidas com construções feitas de acordo com os materiais construtivos disponíveis e mão de obra, existente, criando, desta forma, fortes identidades locais.

O núcleo inicial de Dracena teve sua demarcação feita não apenas em função da ferrovia, que chegou quatorze anos depois de sua fundação, mas também, em função da rodovia que promoveu a ligação com as cidades adjacentes, como Tupi Paulista e Junqueirópolis. Porém, a importância da ferrovia na estruturação do traçado urbano não pode ser negada, uma vez que a existência de um marco de cimento já anunciava que o trem passaria por ali, muito em breve. Dessa forma, o desenho da cidade surge em função dessas duas vias: a futura ferrovia e a, já existente, rodovia.

Para Marx (1980), o avanço acelerado da marcha do café, no oeste do estado com as características do meio de transporte, o ferroviário, devido as suas exigências do seu trajeto e a necessidade de realizarem rapidamente o parcelamento do solo para venda imediata, determinaram a produção de um novo cenário urbano monótono e regular

(Figura

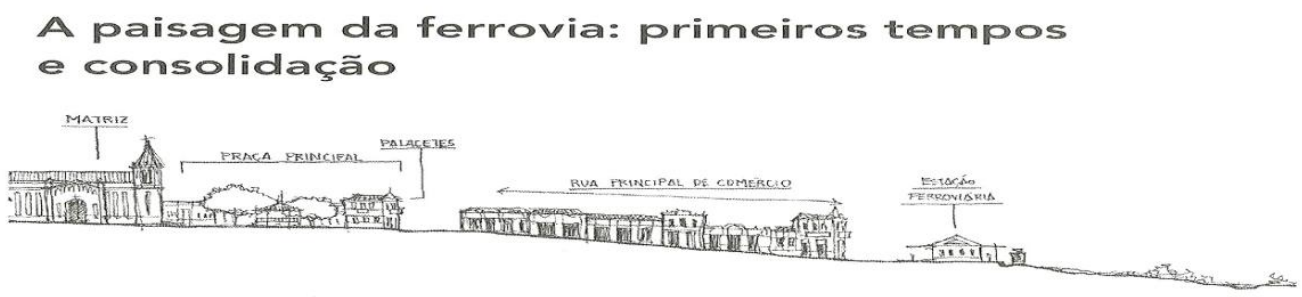

Figura 1. Cenário comum nas cidades fruto da expansão ferroviária do Oeste Paulista. Fonte: Landim, 2004 
Por outro lado, produziram paisagens características, com equipamentos públicos e privados, mais os espaços abertos identificando os locais pelo uso e apropriação socioespacial, com a construção de um lugar de acordo com as condições possíveis de materiais e mão de obra, constituindo-se num registro desse momento inicial do núcleo urbano, e como tal são de interesse para salvaguarda (HIRAO, 2010).

Nas metrópoles e mesmo nas cidades médias e pequenas, os centros históricos passaram por processos de abandono e deterioração, devido a fatores como a não adequação de seus espaços aos novos usos, o surgimento de outros centros e processos de segmentação socioespacial. Como consequência, edifícios, praças e conjuntos deles, foram substituídos ou abandonados e, dessa forma, o conjunto urbano inicial foi descaracterizado. Entretanto, muitos deles ainda permanecem, possibilitando revelar o caráter e identidade particular de cada cidade.

$$
\text { Portanto, }
$$$$
\text { verifica-se }
$$

0 encaminhamento para uma homogeneidade e uniformidade da paisagem urbana das cidades médias paulista, como constata Landim (2004), excetuando-se as estações ferroviárias e as suas esplanadas. Desse modo, esta investigação identificou até que ponto esse processo também aconteceu ou não na cidade de Dracena.
Este estudo traz como abordagem principal as relações morfológicas apoiadas nas questões socioeconômicas e produção do espaço urbano, verificando a função e significado do centro histórico na cidade de Dracena, no dia a dia dos seus protagonistas. Para tal considerou-se a perspectiva de estudo da paisagem trabalhada pelos arquitetos segundo Yazigi (2002), que relaciona a arquitetura ao território, na qual as cidades são formadas por inúmeras formas arquitetônicas reveladoras de história, tecnologia e valores estéticos, que através de sua evolução histórica, novos usos e apropriações socioespaciais modificam não só as formas antigas, como também surgem novas estruturas para atender outras demandas. Desse modo, tais conjuntos urbanos podem constituir-se num patrimônio digno de preservação.

Traz como recorte espacial o núcleo inicial da cidade de Dracena, onde o terminal rodoviário era o elemento central e as edificações implantaram-se ao seu redor. É nos centros históricos onde estão os registros importantes das várias fases de urbanização e essa ambiência precisa ser valorizada e preservada para as novas gerações poderem fazer a leitura dos vários recortes temporais de suas cidades. 


\section{METODOLOGIA}

A princípio a investigação realizou um levantamento bibliográfico que abordasse as questões referentes à preservação patrimonial, seja ela histórica ou cultural, baseando-se nas cartas patrimoniais e teorias da restauração. Em seguida, abordaram-se as intervenções projetuais que se realizam em centros históricos de pequenas e médias cidades, levando em conta a evolução urbana e seu processo de expansão. Dessa forma, depois de sistematizadas, estas informações forneceram subsídios iniciais para 0 desenvolvimento da pesquisa de campo.

A etapa seguinte correspondeu ao trabalho de campo, realizando visitas técnicas a Dracena, para que a paisagem fosse reconhecida e o espaço vivenciado, além de consultas a mapas e fotos históricas. Na sequência, o levantamento e identificação da paisagem da área central e seus equipamentos urbanos de interesse de preservação sintetizou esse momento da pesquisa ao produzir sketchs e croquis.
A etapa final promoveu a sistematização e organização das etapas anteriores, que subsidiaram as análises e reflexões sobre a temática estudada. Para facilitar a análise dos edifícios de importância patrimonial no centro histórico de Dracena, foram definidos quatro recortes temporais que representaram mudanças significativas na estrutura urbana de Dracena.

\section{RESULTADOS}

Através do levantamento fotográfico, foi possível a elaboração de "mapas croquis" e comparações fotográficas afim de identificar o estado de preservação das edificações do centro histórico de Dracena. Para tal análise, foram estabelecidos quatro recortes temporais que representaram mudanças significativas na estrutura urbana da cidade. O primeiro recorte identifica os três primeiros anos da cidade, tendo como edificações importantes apenas o Hotel Municipal e a Farmácia, ambos edificados em madeira

(Figura

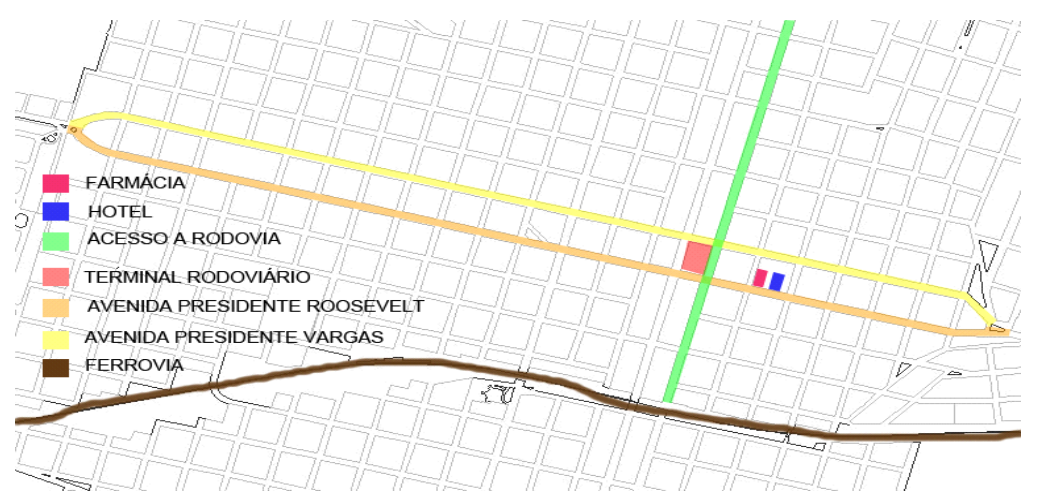

Figura 2. Localização do primeiro hotel e primeira farmácia Fonte: Base cartográfica fornecida pela Prefeitura Municipal de Dracena e editada pela autora. 
O segundo recorte retrata o fim do ano de 1949 até início dos anos de 1950, quando foi instalado o terminal rodoviário e, consequentemente, importantes serviços em seu entorno, como a Prefeitura Municipal, Hotel Municipal, os Correios e o Fórum

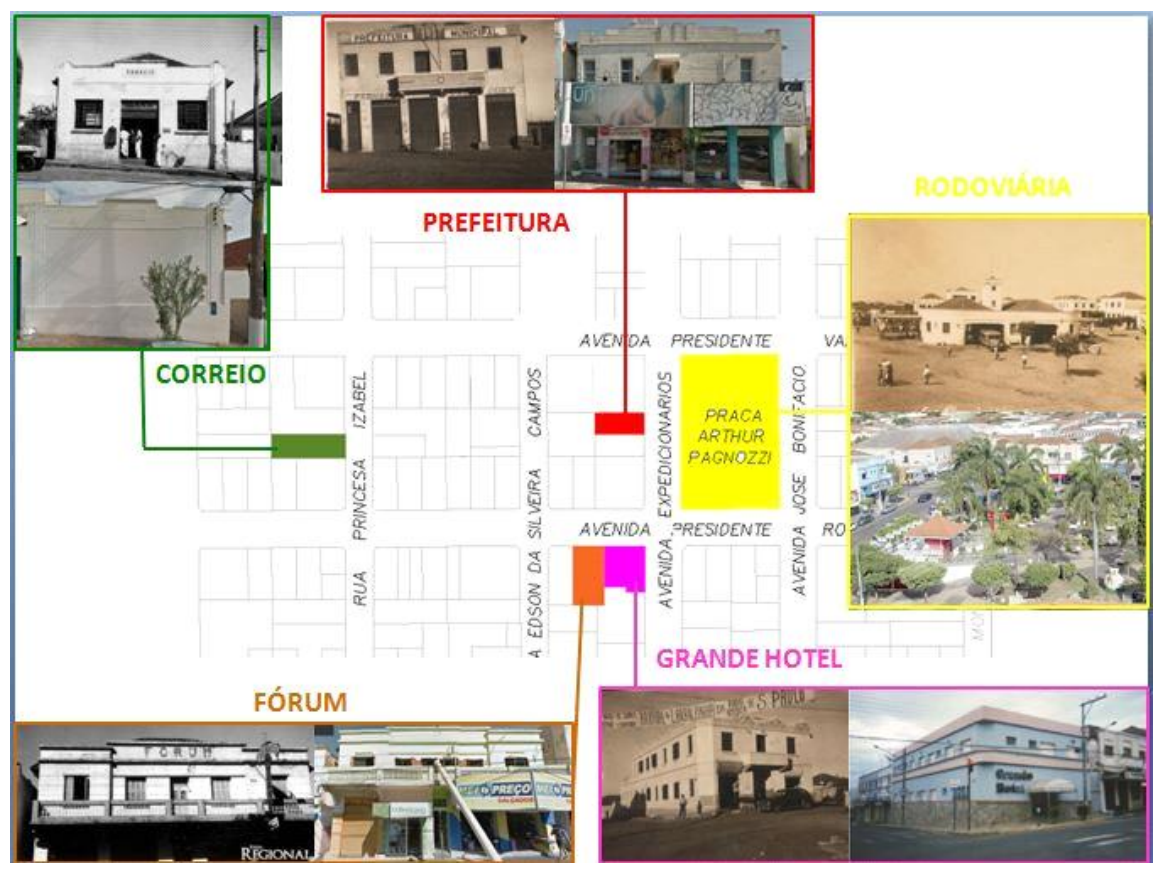

Figura 3. Situação atual das edificações históricas (1948 - 1950) do núcleo urbano inicial de Dracena.

Fonte: Base cartográfica fornecida pela Prefeitura Municipal de Dracena e editada pela autora.

O terceiro recorte temporal representa o início da década de 1950, época em que Dracena apresentou acelerado desenvolvimento e o entorno do terminal rodoviário encontrava-se densamente edificado. É nesta época que importantes serviços, como a Agência Bancária do Banco do Brasil, Cinema, Mercado Municipal e postos de gasolina começam a se instalar (Figura

4). 


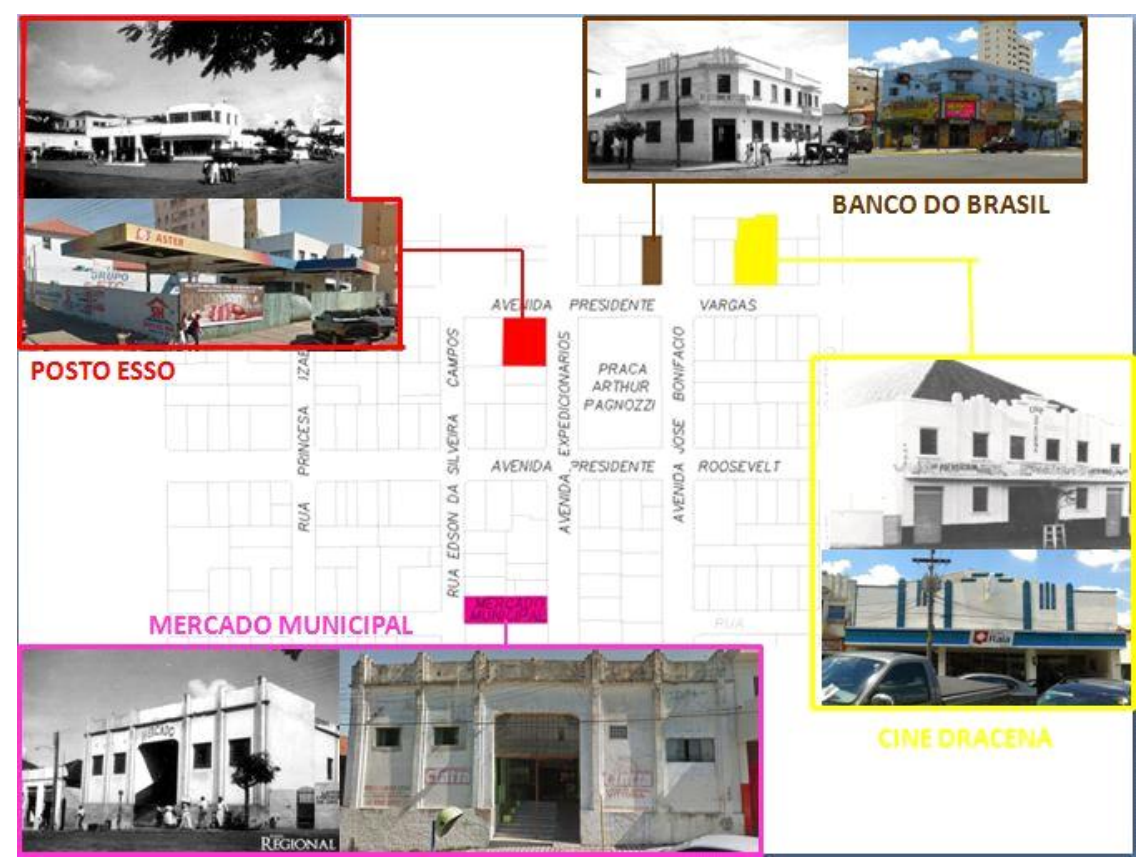

Figura 4. Situação atual das edificações históricas (1950 - 1955) do núcleo urbano inicial de Dracena.

Fonte: Base cartográfica fornecida pela Prefeitura Municipal de Dracena e editada pela autora.

No quarto e último recorte, temos o final da década de 1950, que traz transformações importantes, como a mudança do terminal rodoviário, o mais importante referencial urbano, para outro espaço, dando lugar à Praça da Bandeira. É neste cenário que chega o primeiro trem da Companhia Paulista de Estradas de Ferro, alterando a estrutura urbana de Dracena e contribuindo para sua evolução.

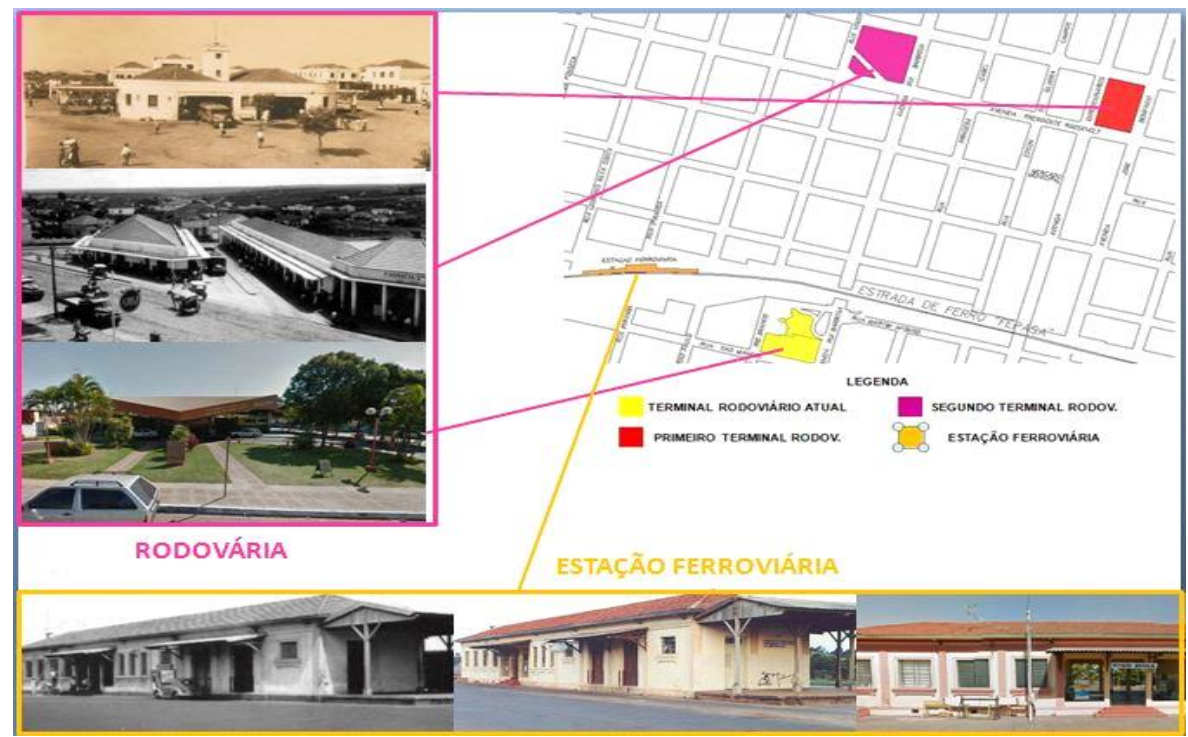

Figura 5. Situação atual das edificações históricas (1955 - 1960) do núcleo urbano inicial de Dracena.

Fonte: Base cartográfica fornecida pela Prefeitura Municipal de Dracena e editada pela autora. 


\section{DISCUSSÕES}

A partir das comparações fotográficas e de idas à campo, conclui-se que a paisagem do centro histórico de Dracena, especialmente no entorno da Praça Arthur Pagnozzi, ainda apresenta importantes suportes materiais de seu passado, através de edificações que datam desde as décadas de 1940 e 1950. Tais edificações apresentam características do estilo arquitetônico ArtDecó, encontram-se bem conservados, em sua maioria, e utilizados para fins comerciais e de serviços.

Com o tempo, adequações às necessidades de usos e apropriações que promoveram intervenções sobre a preexistência construída, nem sempre consideraram a preservação e conservação desse patrimônio urbano e arquitetônico. Nesse sentido, alguns edifícios e espaços abertos foram preservados, outros reformados, outros descaracterizados, outros adequados, outros demolidos, outros abandonados. Contudo, constituem-se em testemunhos significativos da arquitetura e urbanismo produzidos por essa geração que iniciou o processo urbano.

Mas, ao observar a cena urbana contemporânea percebe-se uma tendência para a homogeneização do ambiente construído com o processo de globalização em curso, mesmo com a existência de um discurso de valorização das diferenças
(CASTRIOTA, 2009). Assim, o caráter histórico particular de uma cidade é esquecido pela valorização de uma imagem internacional.

\section{CONCLUSÕES}

Com a análise da evolução urbana de Dracena fundamentada no levantamento bibliográfico e fotográfico, verifica-se que a formação e consolidação da paisagem urbana da cidade de Dracena apresentam características semelhantes a da maioria das cidades da região de Presidente Prudente, as quais foram estruturadas em função da linha férrea. No caso de Dracena, o terminal rodoviário foi o principal referencial urbano até a chegada do trem. Dessa forma, o entorno do terminal foi ocupado com os equipamentos (a igreja, prefeitura, fórum, correios) e casario comerciais e residenciais estrategicamente localizados.

A paisagem urbana do centro da cidade de Dracena, especialmente no entorno da atual Praça Arthur Pagnozzi, ainda apresenta registros materiais de seu passado, possuindo edificações que datam do início do seu processo de urbanização. Estas edificações com características do ArtDecó, estão bem conservados, em sua maioria, e são utilizados para fins comerciais e de serviços. Letreiros e placas que identificam os estabelecimentos "camuflam" os detalhes construtivos das edificações 
históricas, porém preservam essas características arquitetônicas, uma vez que quando retirados a edificação volta ao seu estado original. Para que a Paisagem Urbana seja valorizada e sua salvaguarda garantida, são necessárias ações de educação patrimonial. Como também, o estabelecimento de políticas públicas conciliando os interesses do mercado imobiliário e a preservação do patrimônio urbano e arquitetônico da cidade.

\section{REFERÊNCIAS}

CASTRIOTA, L. B. Patrimônio cultural: conceitos, política, instrumentos. Belo Horizonte: Annablume, 2009.

GOMES, Marco A.A.F. Preservação e urbanismo, encontros, desencontros e muitos desafios. In GOMES, Marco A.A.F.; CORRÊA, Elyane L. Receituações Contemporâneas do Patrimônio. Salvador: UFBA, 2011
HIRAO, H. Arquitetura moderna paulista, imaginário social, uso e apropriação do espaço. Presidente Prudente: 2008 (Tese de Doutoramento FCT/ UNESP). 224p.

LANDIM,Paula da Cruz. Desenho de paisagem urbana: as cidades do interior paulista. São Paulo: Editora UNESP, 2004 Marx, Murilo. Cidade brasileira. São Paulo: Melhoramentos, 1980.

YAZIGI, E. A importância da Paisagem. In (Org.). Turismo e Paisagem. São Paulo: Contexto, 2002

SANTOS, R.E. dos. Dracena, Minha Memória, Minha História [CD].Dracena. 1CD.

SANTOS, R.E. dos. Viajando na História. Dracena.

Recebido para publicação em 19/08/2014 Revisado em 15/09/2014 Aceito em 17/09/2014 